\title{
Inventarisasi Selaginellaceae di Hutan Lindung Aek Nauli Parapat Sumatera Utara
}

\author{
JAMILAH NASUTION ${ }^{1}$, IDA FAUZIAH ${ }^{1}$, FERDINAND SUSILO ${ }^{1}$ \\ ${ }^{1}$ Fakultas Biologi Universitas Medan Area \\ Jl. Kolam No. 1 Medan Estate, Sumatera Utara. 20223 \\ Email: jamilah.nasution83@gmail.com
}

Received 24 December 2017; Received in revised form 19 January 2018; Accepted 2 February 2018; Available online 15 February 2018

\begin{abstract}
This research aims to determine the types of Selaginella in the field and to know the existence of species within a community. This study was conducted by collecting specimens from the field followed by inventory and identification of Selaginella species, as well as recording environmental conditions.The results of this study obtained 5 types of Selaginella: Selaginella intermedia, Selaginella kityyae, Selaginella longariastata, Selaginella ornata and Selaginella willdenovii. Based on their habitat Selaginella intermedia, Selaginella kityyae, Selaginella longariastata and Selaginella willdenovii found in field, have a terrestrial habitus spread, whereas Selaginella ornata is an upright epilithic terrestrial, with each species found mostly in clusters and dominate in an area.
\end{abstract}

Keywords: Protected Forest Aek Nauli, Selaginella

\section{INTISARI}

Penelitian ini bertujuan untuk mengetahui jenis-jenis Selaginella yang ada di lapangan dan untuk mengetahui keberadaan spesies di dalam suatu komunitas. Penelitian ini dilakukan dengan mengoleksi spesimen dari lapangan dilanjutkan dengan inventarisasi dan identifikasi jenis Selaginella, serta mencatat kondisi lingkungan. Hasil penelitian menunjukkan bahwa terdapat 5 jenis Selaginella yaitu Selaginella intermedia, Selaginella kityyae, Selaginella longariastata, Selaginella ornata, dan Selaginella willdenovii. Berdasarkan habitusnya jenis Selaginella intermedia, Selaginella kityyae, Selaginella longariastata, dan Selaginella willdenovii yang ditemukan memiliki habitus terestrial menjalar, sedangkan Selaginella ornata memiliki habitus terestrial epilitik tegak, dengan masing-masing jenis banyak dijumpai berkelompok dan mendominasi dalam suatu area.

Kata kunci: Selaginella, Hutan Lindung Aek Nauli

\section{PENDAHULUAN}

Indonesia dan negara-negara di kawasan Malesia memiliki sejumlah spesies Selaginella, tetapi informasi mengenai takson ini masih terbatas. Famili Selaginellaceae hanya mempunyai satu genus yaitu Selaginella yang terdiri dari 700-750 jenis. Di kawasan Malesia dan Nusantara, terdapat sekitar 200 jenis Selaginella (Tryon dan Tryon, 1982). Di pulau Jawa, diperkirakan terdapat sekitar 24 jenis dengan 5 jenis endemik. Dari jenis-jenis ini sebagian besar kemungkinan berada di ambang kepunahan (Setyawan and Darusman, 2008).

Menurut Camus (1997) diperkirakan jenis Selaginella di pulau lain yaitu Kalimantan (58), Nugini (55), Sumatera (29), dan Sulawesi (21), serta pulau-pulau yang kecil, yaitu Maluku (18) dan Sunda Kecil (9). Sejumlah spesies juga ditemukan di negara-negara lain di kawasan Malesia, yaitu Filipina (48), Thailand (29), Semenanjung Malaya (25) dan Kepulauan Salomon (8). Sari (2011) menyatakan bahwa di Sumatera Utara terdapat 
19 jenis Selaginella, yang meliputi 17 catatan lama, 1 jenis merupakan temuan baru yaitu Selaginella opaca, dan 1 jenis lainnya merupakan jenis yang diduga jenis baru.

Selaginella dilaporkan mengandung alkaloid, saponin, dan fitosterol. Tumbuhan obat ini berkhasiat untuk menghilangkan panas, melancarkan aliran darah, antitoksik, antineoplasma, penghenti pendarahan (hemostasis) serta menghilangkan bengkak (Arini dan Kinho, 2012). Selain itu paku cakar ayam atau rane juga berkhasiat untuk mengatasi batuk, infeksi saluran nafas, radang paru, hepatitis, diare, keputihan, tulang patah, pendarahan, dan kanker (Dalimartha, 2009).

Berdasarkan potensi yang dimiliki oleh famili Selaginellaceae dan mengingat masih kurangnya data tentang jenis Selaginella di Sumatera Utara, maka diperlukan penelitian mengenai inventarisasi Selaginellaceae di Hutan Lindung Aek Nauli Parapat Sumatera Utara.

\section{METODE}

Penelitian ini dilaksanakan pada bulan Juli sampai dengan Desember 2016 di Hutan Lindung Aek Nauli Parapat Sumatera Utara dan di Laboratorium Biologi Universitas Medan Area.

Hutan Lindung Aek Nauli merupakan salah satu hutan alam yang terdapat di Sumatera Utara. Kawasan ini terletak di desa Sibaganding, Kecamatan girsang Sipangan Bolon, Kabupaten Tingkat II Simalungun.
Selain itu, daerah ini juga diapit oleh dua kota, yaitu Parapat yang berjarak $\pm 10,5 \mathrm{~km}$ dan kota Pematang Siantar $\pm 33,5 \mathrm{~km}$. Sedangkan jaraknya ke kota Medan adalah $\pm 163,5 \mathrm{~km}$ dengan sarana jalan dan pengangkutan yang memerlukan waktu 4 jam perjalanan.

Penelitian ini bersifat eksplorasi inventarisasi jenis Selaginella di lapangan dengan menggunakan metode purposive sampling yaitu mengambil dan mengoleksi objek yang sudah ditentukan secara langsung di lapangan. Diawali dengan observasi lapangan untuk melihat kondisi lingkungan jenis Selaginella berada, kemudian dilakukan pengoleksian spesimen, mengambil dokumentasi, menginventarisasi jenis Selaginella serta mencatat kondisi lingkungan seperti habitat dan habitusnya. Selanjutnya, setelah spesimen dikumpulkan dilakukan identifikasi jenis Selaginella dengan menggunakan buku identifikasi. Setelah dilakukan identifikasi di lapangan, maka dilanjutkan identifikasi di laboratorium untuk melihat perbedaan daun lateral, daun median, dan daun aksilar pada spesimen.

\section{HASIL}

Berdasarkan pengamatan spesimen dan eksplorasi yang telah dilakukan, ditemukan sebanyak 5 jenis Selaginella di Hutan Lindung Aek Nauli Parapat, yaitu Selaginella intermedia, Selaginella kityyae, Selaginella longariastata, Selaginella ornata, dan Selaginella willdenovii (tabel 1).

Tabel 1. Jenis Selaginella di Hutan Lindung Aek Nauli Parapat

\begin{tabular}{cccc}
\hline No. & Familia & Spesies & Habitus \\
\hline 1 & & Selaginella intermedia & Terestrial menjalar \\
\hline 2 & & Selaginella kittyae & Terestrial menjalar \\
\hline 3 & Selaginellaceae & Selaginella longariastata & Terestrial menjalar \\
\hline 4 & & Selaginella ornata & Terestrial epilitik tegak \\
\hline 5 & & Selaginella wildenovii & Terestrial menjalar \\
\hline
\end{tabular}

\section{PEMBAHASAN}

Kelima jenis Selaginella yang ditemukan di Hutan Lindung Aek Nauli Parapat, yaitu Selaginella intermedia, Selaginella kityyae, Selaginella longariastata, Selaginella ornata, dan Selaginella willdenovii banyak ditemukan di sepanjang pinggiran sungai. Berdasarkan habitusnya, jenis Selaginella intermedia, Selaginella kityyae, Selaginella longariastata, dan Selaginella willdenovii yang ditemukan merupakan terestrial menjalar dan banyak dijumpai tinggal berkelompok dan mendominasi dalam suatu area, sedangkan Selaginella ornata merupakan terestrial 
epilitik tegak yang juga banyak dijumpai tinggal berkelompok dan mendominasi suatu area. Menurut Sari (2011) penyebaran Selaginella di Sumatera Utara dapat ditentukan dari pengamatan spesimen, publikasi terdahulu dan eksplorasi di lapang. Selaginella dapat dijumpai di daerah Langkat (Tanjung Pura, Bukit lawang), Karo (Kabanjahe, Sibolangit, Gunung Sinabung), Asahan, Pematang Siantar, Parapat, Porsea, dan Nias. Selaginella banyak dijumpai pada hutan primer dan sekunder dengan intensitas cahaya matahari yang rendah hingga tinggi. Marga ini dapat hidup pada kisaran habitat yang luas, mulai dari daerah dataran rendah hingga ke daerah sub alpine di pegunungan. Selaginella di Sumatera Utara kebanyakan merupakan jenis terestrial, namun dapat juga dijumpai epifit dan epilitik yang menempel pada bebatuan bersama-sama dengan lumut.

Tabel 2. Identifikasi Jenis Selaginella

\begin{tabular}{ll}
\hline No. & \multicolumn{1}{c}{ Deskripsi } \\
\hline & Terestrial, menjalar. Pola Percabangan tidak terlihat bagian sumbu \\
& utamanya, kadang-kadang terlihat percabangan yang ditandai dengan \\
& sumbu utama yang terlihat jelas, percabangan keseluruhan \\
& menggarpu 5-20 kali. Batang diameter $0,5-2,9$ mm, licin, berwarna \\
& cokelat. Rhizopor aksilar, hanya dijumpai pada bagian bawah dari \\
& batang, tidak di sepanjang batang, diameter 0,3-2,6 mm. Daun \\
& dimorfik, berwarna abu-abu hingga hijau gelap. Daun lateral $1-6 \mathrm{x}$ \\
& $0,8-2,2 \mathrm{~mm}$, tidak saling menimpa, semakin ke atas semakin \\
& berdekatan, berbentuk jorong, ujung daun runcing hingga tumpul, \\
& pangkal bulat hingga sungsang, asimetrik, tepi daun bergerigi pada \\
Selaginella intermedia (Bl.) & satu sisi, bergerigi kadang-kadang sangat halus, hampir tidak \\
Spring. & kelihatan, pertulangan daun tidak terlihat, permukaan daun licin, \\
& berligula. Daun median $1,3-3,1$ x $0,3-1,5$ mm, saling menimpa, bulat \\
& telur hingga oval, berbentuk seperti sabit, asimetrik, ujung daun yang \\
& panjang seperti ekor, panjang arista $1 / 4$ hingga $1 / 2$ kali dari panjang \\
& lamina, pangkal bulat hingga berbentuk seperti hati, pangkal daun \\
& dengan sisi yang tidak sama atau miring, tepi daun yang bergerigi \\
& halus pada kedua sisi, pertulangan daun terlihat jelas, permukaan \\
& daun licin. Daun aksilar $1,5-4 \mathrm{x} 0,6-1,8$ mm, bulat teur hingga \\
& memanjang berbentuk tombak, ujung daun yang tumpul hingga \\
& runcing pangkal daun tidak membengkok seperti telinga, bulat \\
& hingga sungsang, tepi daun bertoreh hingga bergerigi pada kedua sisi, \\
permukaan daun licin, berligula
\end{tabular}

Terestrial, menjalar. Pola Percabangan pseudopinnate sederhana, percabangan keseluruhan berjarak $0.5-4 \mathrm{~cm}$, lanceolate hingga oblong, panjang 4-21 cm, $\pm 5-9$ pinna pada satu sisi, panjang pinnule 0,5-4 cm, 3-20 pinnule pada satu sisi, menyirip dan menggarpu, bercabang 1-6 kali. Batang diameter 0,5-3,8 mm, permukaan ditutupi oleh daun median, berwarna cokelat hingga kekuningan. Rhizopor berjarak 0,7-3 cm, dorsal, aksilar, diameter 0,3-1,6 mm. Daun dimorfik, berwarna hijau terang hingga hijau kusam. Daun lateral 0,8-6 x 0,2-2,5 mm, tidak saling menimpa, berdekatan pada bagian ujung, oval hingga berbentuk jorong, ujung runcing hingga meruncing, pangkal seperti bentuk hati hingga membengkok, tepi daun rata, pertulangan daun tidak terlihat jelas, permukaan daun licin. Daun median 0,6-6,5 x 0,2-2 mm, masing-masing ruas terdiri dari dua daun, dan masing-masing segmen berjauhan, kadangkadang berdekatan pada bagian ujung, oval hingga berbentuk sabit, ujung meruncing hingga ujung daunnya pendek, pangkal berbentuk hati hingga membengkok, tepi daun rata, pertulangan daun terlihat jelas, lebih menonjol pada bagian ujung dari daun, permukaan daun 


\begin{tabular}{ll}
\hline & licin. Daun aksilar 1-7,5 x $0,5-2 \mathrm{~mm}$, oval hingga bulat, ujung \\
membulat, meruncing hingga tajam, pangkal daun tidak \\
membengkok seperti telinga, membulat hingga berbentuk seperti \\
hati, tepi daun rata. \\
\hline Terestrial, menjalar. Pola Percabangan yang tidak terlihat bagian \\
sumbu utamanya dengan banyak percabangan dikotom. Batang \\
diameter $0,6-2,1 \mathrm{~mm}$, berwarna kecokelatan, licin. Rhizopor berjarak \\
satu sama lain $1,5-2 \mathrm{~cm}$, aksilar-dorsal, diameter 0,2-0,5 mm. Daun \\
dimorfik, berwarna hijau hingga hijau kekuningan. Daun lateral 1-7 \\
x 0,4-2 mm, berbentuk jorong, ujung runcing, pangkal sungsang \\
hingga membulat pada satu sisi, pangkal daun miring, tepi daun \\
bergerigi pada bagian ujung, tepi daun dengan rambut yang jarang \\
hingga rapat menuju bagian pangkal, pertulangan daun tidak terlihat \\
dengan jelas pada sisi adaksial, terlihat pada sisi abaksial, permukaan \\
daun licin, berligula. Daun median $1,5-4$ x $0,4-1,5$ mm, berdekatan, \\
saling menimpa, bulat telur hingga oval, ujung daun panjang, \\
berambut pada ujung dari arista, panjang arista satu kali panjang \\
lamina, pangkal sungsang hingga berbentuk hati, tepi daun tepi daun \\
dengan rambut yang jarang hingga rapat, pertulangan daun terlihat \\
jelas, lebih jelas pada bagian ujung, permukaan daun licin. Daun \\
aksilar 2,1-4,5 $0,8-2$ mm, ovate triangular hingga berbentuk seperti \\
tombak, ujung daun runcing, pangkal daun tidak membengkok \\
seperti telinga, sungsang hingga membulat, tepi daun rata hingga \\
bergerigi halus pada bagian ujung, di bagian pangkal daun tidak \\
membengkok seperti telinga.
\end{tabular}

Terestrial, epilitik, tegak. Pola Percabangan pseudopinnate, anak cabang bercabang pseudopinnate, lanceolate hingga deltoid secara keseluruhan, pinna lanceolate hingga oblanceolate, panjang 0,5-13 $\mathrm{cm}, 2-13$ pinna pada satu sisi, pinna berjarak masing-masing 0,3-2 $\mathrm{cm}$, panjang pinnule 0,3-4 $\mathrm{cm}, 1-10$ pinnule pada satu sisi, menggarpu 1-11 kali. Batang diameter 0,2-2,1 mm, licin, berwarna kekuning-kuningan. Rhizopor berjarak masing-masing 1-3 cm, aksilar, aksilar-dorsal, diameter 0,2-0,9 mm. Daun dimorfik, berwarna hijau hingga hijau gelap. Daun lateral 0,5-4 x 0,5-1,6 mm, saling menimpa, bulat triangular hingga jorong, ujung membulat, tumpul hingga runcing, pangkal membulat hingga berbentuk hati, Grev.) Spring asimetrik, pangkal daun miring, tepi daun bergerigi pada kedua sisi, kadang-kadang memiliki rambut yang jarang pada bagian pangkal, pertulangan daun tidak terlihat, permukaan daun licin, berligula. Daun median 0,5-2 × 0,3-1 mm, berdekatan hingga berjarak, bulat telur hingga bulan sabit, ujung meruncing, pangkal daun miring, membulat hingga berbentuk hati, tepi daun bergerigi hingga tepi daun dengan rambut yang jarang pada kedua sisi, pertulangan daun menonjol, permukaan daun licin. Daun aksilar 0,6-2,2 x 0,4-1,5 mm, oval hingga berbentuk tombak, ujung sedikit runcing hingga runcing, pangkal daun tidak membengkok seperti telinga, membulat hingga berbentuk seperti hati, tepi daun bergerigi, permukaan daun licin.

Terestrial, menjalar. Pola Percabangan pseudopinnate, sumbu terkecil bercabang pseudopinnate, pinna lanceolate, panjang 1-16 $\mathrm{cm}, 3-12$ pinna pada satu sisi, pinna berjarak masing-masing 1,3-4,5 $\mathrm{cm}$, panjang pinnule $0,8-6,5 \mathrm{~cm}, 2-12$ pinnule pada satu sisi, menyirip (Desv.) Baker dan menggarpu. Batang diameter 0.3-2.5 mm, permukaan licin, berwarna kecokelatan hingga kekuning-kuningan. Rhizopor berjarak masing-masing 1-1,5 cm, aksilar-dorsal, diameter 0,2-0,9 mm. Daun dimorfik, berwarna hijau terang hingga hijau. Daun lateral 1-4 x 0,4- 
$2 \mathrm{~mm}$, berjauhan, tidak saling menimpa, ovate triangular hingga jorong, ujung tumpul hingga runcing, pangkal berbentuk seperti hati hingga cuping daun, pangkal dau miring, tepi daun rata, pertulangan daun terlihat, permukaan daun licin. Daun median 0,4-2,8 x 0,2-1,5 $\mathrm{mm}$, berjauhan, oval hingga seperti bulan sabit, ujung daun yang ramping dan tumpul hingga meruncing, pangkal daun berbentuk seperti hati hingga membengkok, tepi daun rata, pertulangan daun tidak terlihat, permukaan daun licin. Daun aksilar 1-2,5 x 0,6-1,8 $\mathrm{mm}$, bulat hingga oval, ujung membulat, pangkal daun yang terlihat seperti telinga, tepi daun rata.

\section{KESIMPULAN}

Berdasarkan hasil penelitian diperoleh kesimpulan bahwa di Hutan Lindung Aek Nauli Parapat terdapat 5 jenis Selaginella yaitu Selaginella intermedia, Selaginella kityyae, Selaginella longariastata, Selaginella ornata, dan Selaginella willdenovii. Berdasarkan habitusnya jenis Selaginella intermedia, Selaginella kityyae, Selaginella longariastata, dan Selaginella willdenovii ditemukan pada habitus terestrial menjalar, sedangkan Selaginella ornata ditemukan pada habitus terestrial epilitik tegak yang masing-masing jenisnya banyak dijumpai berkelompok dan mendominasi suatu area.

Perlu dilakukan penelitian lanjutan berdasarkan ketinggian tempat dan pengukuran faktor fisika kimia lingkungan, agar diperoleh data yang dapat menggambarkan kondisi ekologi di Hutan Lindung Aek Nauli Parapat Sumatera Utara.

\section{DAFTAR PUSTAKA}

Arini DID dan Kinho J. 2012. Keragaman Jenis Tumbuhan Paku (Pteridophyta) di
Cagar Alam Gunung Ambang Sulawesi Utara. Manado: Balai Penelitian Kehutanan Manado.

Camus JM. 1997. The genus Selaginella (Selaginellaceae) in Malesia. in Dransfield J, Coode MJE, Simpson DA. Plant diversity in Malesia III. Proceeding of the third International Flora Malesiana Symposium 1995. Kew: Royal Botanic Garden. 59-69

Dalimartha S. 2009. Atlas Tumbuhan Obat Indonesia. Jilid 6. Depok: Puspa Swara.

Sari WDP. 2011. Selaginella di Sumatera Utara. [Tesis]. Bogor: Institut Pertanian Bogor.

Setyawan AD, Darusman LK. 2008. Review: biflavonoid compounds of Selaginella Pal. Beauv. and its benefit. Biodiversitas. vol 9(1): 64-81. doi.org/10.13057/biodiv/d120209.

Tryon RM and Tryon AF. 1982. Fern and Allied Plants, with Special Reference to Tropical America. New York: Springer. 